\title{
LA RELIGIÓN CIVIL EN LA TEORÍA DE BARUCH SPINOZA
}

\section{CIVIL RELIGION IN BARUCH SPINOZA'S THEORY}

\author{
Alberto Wagner Moll ${ }^{1}$ \\ Universidad Pontificia de Comillas de Madrid
}

Recibido: 19 abril 2020

Aceptado: 30 agosto 2020

Resumen: El siguiente trabajo busca sacar a la luz cuál es la noción de religión que vertebra la obra de Spinoza, para así encontrar su función dentro de la sociedad y en relación con el Estado. Para ello se analiza pormenorizadamente el Tratado teológico-político, desde el análisis histórico de la Biblia hasta su interpretación de la relación entre Estado y religión, y se usan otros textos como soporte, principalmente la Ética.

Palabras clave: Spinoza, Religión, Estado, Piedad, Conatus.

\begin{abstract}
This work seeks to bring to light the notion of religion that underpins Spinoza's work in order to determine its role within society and its connections to the State. To do so, the Treatise on Theology and Politics is analyzed in depth, from the historical analysis of the Bible to the interpretation of the relationship between State and religion; other texts, mainly Ethics, are used to support this analysis.
\end{abstract}

Key words: Spinoza, Religion, State, Piety, Conatus. 


\section{Introducción}

La religión en Occidente es, en la actualidad, un tema polémico: un gran número de personas creen que supone un atraso para la sociedad, que impone pseudo verdades místicas y perjudica el hacer científico e intelectual en general ${ }^{2}$. Por otra parte, hay un acusado número de personas que defienden la postura contraria, según la cual la religión es la esencia vital de un pueblo, sin la cual las personas existen en un pozo de inmoralidad y nihilismo ${ }^{3}$.

Para confrontar una problemática de tal envergadura, es útil buscar entre los pensadores a aquellos que discurrieron sobre ella. Entre ellos, Spinoza ocupa un lugar preferente en la actualidad, debido a su postura conflictiva ${ }^{4}$. Efectivamente, el hecho de que Spinoza no quedara ligado a un dogma religioso concreto hace que su pensamiento se amolde con mayor facilidad a las inquietudes de una época en que la religión ha perdido su primacía social, al menos en Occidente. No fue, como la mayoría de sus contemporáneos, un defensor de la ortodoxia que estaba vigente en su país, sino que abogaba por un concepto de religión universal cuyo foco estaba situado en el comportamiento de los individuos, en su virtud cívica, más que en su fe interior. Así pues, en una sociedad como la nuestra, donde el poder civil determina la jerarquía social, adentrarnos en una teoría como la de Spinoza, que parte del Estado y no de presupuestos teológicos, es harto clarificador.

Spinoza crea su teoría de la religión desde una exégesis de la Biblia, polemizando con los comentaristas judíos más reputados, como Maimónides o Ibn Ezra. Por lo tanto, su teoría está construida desde las Sagradas Escrituras y no tiene en cuenta más religiones que la cristiana y la judía. Esto podría significar que, frente a la pluralidad de credos que encontramos en nuestras sociedades actuales, la parquedad de religiones analizadas por Spinoza supondría que su teoría ha quedado desfasada. Sin embargo, la realidad es justo la contraria. La conclusión que extrae Spinoza del análisis de las Sagradas Escrituras es que éstas no son divinas ni santas más que en la medida en que ayudan al hombre en su actividad cívica.

2. Tal como afirma Richard Dawkins, uno de los ateos contemporáneos más conocido, quien, en el segundo capítulo de su documental The root of all evil?, de 2006, afirma que "La fe es la gran escabullida, la gran excusa para evitar la necesidad de pensar y evaluar las diferencias. La fe es creer a pesar (o incluso tal vez debido a) la falta de evidencias".

3. Ver: Cohen, A., Moon, J. "Psychology: Atheism and moral intuitions". Nat Hum Behav 1, 0157 (2017). https://doi.org/10.1038/s41562-017-0157. En este artículo, se analizan los resultados de un estudio según el cual las personas, tanto ateas como creyentes, relacionan en mayor medida el ateísmo con la falta de valores y la criminalidad.

4. Acerca de la excomunión de Spinoza y del contexto religioso en que se produce, ver Alfredo D. Vallota, "Teología y política de la excomunión en Spinoza", Episteme, vol. 36, no.2 (2016).

Thémata. Revista de Filosofía No62 (2020) pp.: 57-70. 
Por lo tanto, como este trabajo tiene por objetivo exponer la teoría de la religión del pensador marrano, partirá de un análisis de su filosofía general, expuesta en su Ética demostrada según el orden geométrico, para después embarcarnos en la teoría de la religión y, finalmente, la relación de la religión con el Estado, aspectos ambos que se encuentran en el Tratado teológico-político. De este modo, podremos observar cómo la religión en Spinoza se aleja de la concepción trascendentalista propia de la filosofía medieval para aproximarse a la concepción de religión civil, propia de los autores romanos. Frente a una religión metafísica, el pensador judío aboga por una religión política.

\section{Dios y el hombre}

Spinoza, enmarcado usualmente en lo que se llama el racionalismo moderno, sostiene que Dios es la Sustancia universal de todas las cosas ${ }^{5}$, y que todas ellas expresan de forma causalmente necesaria esta esencia divina, como expresa en el Tratado teológico-político al afirmar que "Por gobierno de Dios, entiendo el orden fijo e inmutable o la concatenación de las cosas naturales"6. Así pues, Dios no es un ente trascendente, sino el conjunto infinito de la realidad, con todos sus modos y atributos. Esto supone una negación frontal de la creación ex nihilo, dogma central de la teología cristiana. Además, cada ente particular expresa la esencia eterna de Dios a su modo, e intenta que su esencia implique su existencia, es decir; intenta perpetuarse en el Ser. Este esfuerzo por persistir es lo que Spinoza llama conatus ${ }^{7}$, y hace que los entes conciban el universo desde su propia esencia: universalizan su propia esencia para intentar imponerla infinitamente. Esto acontece también al ser humano ${ }^{8}$, quien percibe el universo desde su propia esencia, no desde la infinitud de Dios. Por lo tanto, la noción que el ser humano tiene de Dios no coincide con la esencia infinita de Dios, sino con la suya propia. Y así, "aquello que la razón define como malo, no es malo en relación al orden y a las leyes de la naturaleza, sino únicamente en relación a las leyes de nuestra naturaleza"9. El ser humano se diferencia específicamente del resto de seres en que su alma es capaz

5. Spinoza, Baruch: Ética, libro I, proposición XV, p. 16 “Todo lo que es, es en Dios, y nada puede ser ni concebirse sin Dios"

6. Spinoza, Baruch: Tratado teológico-político, p. 118

7. Spinoza, Baruch: Ética, libro III, proposición VI, p. 112 "Cada cosa se esfuerza, cuanto está en ella, por perseverar en su ser"

8. Spinoza, Baruch: op. cit., libro II, proposición XIII, p. 60 "El objeto de la idea que constituye el alma humana es el cuerpo, o sea, cierto modo de la Extensión existente en acto, y nada más"

9. Spinoza, Baruch: Tratado teológico-político, p. 224

Thémata. Revista de Filosofía No62 (2020) pp.: 57-70. 
de conocer a Dios mediante las nociones comunes a la esencia divina, o por la ciencia intuitiva, porque su alma es lo suficientemente potente para obrar de este modo. Así, aunque no pueda conocer la esencia de Dios en su infinitud, sí que puede hacerlo de un modo universal y adecuado para el género humano, de ahí que pueda establecer disciplinas del pensamiento comunes a toda la especie, como la filosofía o la religión.

De este modo, el ser humano construye la religión a partir de su propia esencia, como no podría ser de otra manera, y la función de ésta estará inserta en la existencia humana, no como una herramienta extraña, sino como un utensilio que cubre unas necesidades concretas y que ayuda a los hombres en su esfuerzo por perseverar en la existencia.

\section{Religión}

Spinoza se propone analizar la religión y la relación que esta tiene con el Estado con el objetivo de ver en qué medida puede ser útil la propia religión a la república. Con este fin, Spinoza se propone analizar la relación entre la Biblia, el antiguo estado hebreo y las modernas naciones europeas. No se detiene en indagaciones acerca de otras religiones, como podrían ser el politeísmo griego o el islam porque, en primer lugar, Spinoza, de tradición hebrea, conoce especialmente bien esta religión (incluyendo en ella el cristianismo, del que habla largo y tendido) y es desconocedor en gran medida de los otros cultos. En segundo lugar, la obra de Spinoza es un tratado con claros fines prácticos; no es una indagación puramente especulativa o universal, como sí lo es su Ética, sino una investigación que responde a un contexto político concreto: las guerras de religión en Holanda y en toda Europa, y su excomulgación de la fe judía.

Por ello, Spinoza estructura su análisis de la religión en tres grandes partes: primero, sobre los profetas, los milagros y las ceremonias, después, sobre la historicidad de la Biblia, la autoría de la misma y otros avatares y, por último, el objetivo de las Sagradas Escrituras y en qué medida sirven al orden cívico.

Pero antes de adentrarnos en el análisis pormenorizado de la religión hebrea, recojamos la definición que hace Spinoza de la religión en general. Spinoza dice que la religión es "cuanto deseamos y hacemos, porque somos su causa en cuanto que tenemos la idea de Dios o en cuanto que conocemos a Dios"10, y, en un sentido práctico, "se debe definir diciendo que consiste simplemente en pensar de Dios tales cosas que, ignoradas, se destruye la obediencia a Dios, y que, puesta esta obediencia, se las presupone

10. Spinoza, Baruch: Ética, libro IV, proposición XVII, Escolio 1, p. 208.

Thémata. Revista de Filosofía No62 (2020) pp.: 57-70. 
necesariamente"11. Es decir, la religión es conocer o suponer que Dios (o la esencia de todas las cosas) es de tal modo que nuestro mayor beneficio consiste en obrar en pro de nuestra felicidad máxima, que se logra mediante el control de las pasiones, el dominio de la virtud y el amor al prójimo porque

\footnotetext{
A los hombres es ante todo útil asociarse entre sí y ligarse con aquellos vínculos con los que hagan en forma más apta para todos de ellos un solo individuo y obrar, exclusivamente, lo que sirve para consolidar amistades ${ }^{12}$.
}

Por lo tanto, la religión consiste en asumir las premisas éticas que la filosofía nos da mediante el conocimiento de las verdades eternas. La utilidad de la religión, en tanto que logra el mismo objetivo que la filosofía, será estudiada más adelante en este trabajo. Vayamos ahora a la investigación sobre los profetas y las ceremonias.

\subsection{Acerca de los profetas, las ceremonias y los milagros}

Los profetas son aquellos que comunican "el conocimiento cierto de una cosa, revelado por Dios a los hombres" ${ }^{13}$. Sin embargo, este conocimiento se diferencia del denominado natural en que no es común a toda la especie humana y que es solo asumible mediante fe, es decir, del que no cabe demostración racional. Los profetas no son personas especialmente inteligentes, sino que estaban dotados en gran medida de piedad y virtud y poseían una gran potencia imaginativa ${ }^{14}$. Esto no significa que los profetas "se imaginaran cosas", en el sentido común actual, sino que tenían un don especial para recibir revelaciones de la esencia de Dios a través de elementos sensibles, tal y como los filósofos tienen la capacidad de entender esta misma esencia a través del juicio racional. Las profecías, para que fueran creídas por el pueblo (pues su fin era inducir al vulgo a la moral) debían ir acompañadas de algún tipo de certeza que por sí mismas no contenían; debían ir acompañadas de signos sensibles que las confirmaran a los ojos de los testigos de la profecía.

Por lo tanto, como los profetas no son todos de una misma época, sino que viven en momentos distintos de la historia del pueblo de Israel, estas expresiones indemostrables de la esencia divina debían adaptarse al contexto histórico-social de cada momento. Spinoza es de los primeros autores que pone el acento en la historicidad de la Biblia y en las variaciones del pueblo hebreo que hay que tener en cuenta para analizar los diversos

11. Spinoza, Baruch: Tratado teológico-político, p. 311

12. Spinoza, Baruch: Ética, libro IV, capítulo XII, p. 241

13. Spinoza, Baruch: Tratado teológico-político, p. 74

14. Sobre la noción spinosista de imaginación en relación con los profetas, ver Víctor Sanz, "Filosofía y religión en Spinoza", Estudios Filosóficos, n¹32, 1997.

Thémata. Revista de Filosofía No62 (2020) pp.: 57-70. 
textos de la Escritura, y esto es un claro ejemplo. Así pues, no podía profetizar igual Isaías, cortesano y erudito, que Amós, campesino y analfabeto, ya que, debido a sus diferencias socioculturales, eran susceptibles de ser impresionados por diferentes cosas. Al igual que, mientras un europeo se asustaría al ver una tarántula, un australiano seguramente mantendría la calma, en función de la relación que mantuvieran los profetas con ciertos objetos la posibilidad de que estos les impresionaran era mayor o menor. El mensaje divino se adapta, por lo tanto, a la esencia del profeta y del pueblo al que debe comunicarse, con el fin de que estos obedezcan la ley divina que aquel comunica.

$\mathrm{Y}$ es tan agudo el historicismo espinosista, entroncado en su concepción universal y naturalista del hombre, que considera, en primer lugar, que la felicidad o dicha del pueblo judío como pueblo elegido no es la felicidad superior ${ }^{15}$ a la que puede aspirar el hombre, y que los profetas no existieron únicamente entre las gentes de este pueblo, como es el caso de Balaam. Dios únicamente fue propicio a los hebreos particularmente en el auxilio externo ${ }^{16}$ a su Estado, mientras éste duró.

Concluimos, pues: dado que Dios es igualmente propicio a todos y que los hebreos sólo han sido elegidos por Dios en relación a la sociedad y al Estado, ningún judío, considerado exclusivamente fuera de la sociedad y del Estado, posee ningún don de Dios por encima de los demás y no se diferencia en nada de un gentil ${ }^{17}$.

Del mismo modo, los milagros son entendidos como muestras de ese poder divino que ayuda o perjudica a los hombres en función de que hayan obedecido rectamente el mandato de Dios. Aunque es útil para la obediencia civil (fin último de la religión), la creencia en los milagros es completamente errónea según Spinoza, puesto que se basa en una división ficticia entre poder natural y sobrenatural" ${ }^{2}$. Según esta distinción, existiría una dimensión que está por encima de la Naturaleza, a la cual pertenecen todas aquellas cosas de que no podemos dar explicación, como por ejemplo, una aparición fantasmagórica. Sin embargo, y partiendo de la ontología de Spinoza (apartado 1 de este texto), vemos que algo que fuera contra la Naturaleza de algún modo,

15. Spinoza, Baruch: Tratado teológico-político, p. 116 "La verdadera felicidad y beatitud de cada individuo consiste en la fruición del bien y no en la gloria de ser uno solo, con exclusión de los demás, el que goza del mismo": es decir, el pueblo hebreo no encontró mayor felicidad porque su dicha no fuera compartida por el resto de pueblos, sino más bien al contrario, ya que esto engendró soberbia y odio hacia las otras naciones.

16. Spinoza, Baruch: op. cit., p. 119: "toda utilidad que pueda provenirle, además, del poder de las causas externas".

17. Spinoza, Baruch: op. cit., p. 125.

18. Spinoza, Baruch: op. cit., p. 168 "Es decir, que el vulgo estima que, mientras la naturaleza actúa de la forma habitual, Dios no hace nada; y que, a la inversa, el poder de la naturaleza y las causas naturales están ociosos, mientras Dios actúa”

Thémata. Revista de Filosofía No62 (2020) pp.: 57-70. 
o que fuera distinto a ella, sería extrínseco a Dios, y, por lo tanto, imposible, cosa que confirma Spinoza al sentenciar tajantemente: "Concluimos, pues, sin restricción alguna, que todo lo que se dice en la Escritura que sucedió realmente, sucedió necesariamente, como todas las cosas, según las leyes de la naturaleza"19. Por lo tanto, el milagro ha de ser una invención humana, que proyecta nombres superfluos a las cosas cuya causa desconoce y que le parecen de un poder mucho mayor que las cosas a que está habituada. Los milagros, entonces, son útiles para los profetas en la medida en que impresionan con gran fuerza al vulgo y le incitan a la obediencia ${ }^{20}$. Como vemos, los profetas actúan en pos de la utilidad cívica, no en busca de la verdad divina, de la que son, realmente, tan ignorantes como el pueblo al que educan. Los profetas tienen la certeza de cómo se obra rectamente, pero no pueden justificarla racionalmente, y Dios les revela mediante signos sensibles cómo hacer llegar la certeza moral al pueblo de una forma práctica.

Del mismo modo, las ceremonias son la institucionalización de estos saberes morales, que se formalizan con el fin de que se sigan comunicando más allá de la vida de los profetas.

\subsection{Historicidad de la Biblia}

Aunque, actualmente, sea algo normal el estudio de la veracidad histórica y del contexto sociocultural en que se escribieron y transmitieron los diversos libros que conforman la Biblia, no es hasta la modernidad que no se comienza a realizar una exégesis de este estilo ${ }^{21}$, siendo el propio Spinoza uno de los pioneros en este método. El sistema que llevará a cabo será el siguiente: desde los propios textos conservados, se ha de investigar el uso habitual del hebreo de la época, qué querían decir originalmente los profetas y cuál es su contexto.

El lenguaje hebreo, como todos los idiomas, ha sufrido modificaciones a lo largo de su historia (como inclusión o supresión de conjunciones, de vocales u otros términos) y se desconoce cuál era el significado original de muchos textos, ya sea por pérdida de los documentos originales o por falta de datos contextuales. Para no detenernos en la problemática filológica que expone detalladamente Spinoza en esta parte del Tratado, resumiremos diciendo que, pese a las dificultades que presentan una gran

\section{Spinoza, Baruch: op. cit., p. 183}

20. Para una aproximación pormenorizada a la teoría spinosista sobre el uso de la superstición como herramienta política, ver Iván Ramón Rodríguez Benavides "Capítulo 1: El Miedo Político: La Superstición”, en Pasiones, Libertad y Estado en Spinoza (tesis doctoral), Universitat de Barcelona, 2015.

21. Sobre la hermenéutica de Spinoza, ver Ferrariz, Maurizio: "Capítulo 3.2: La hermenéutica bíblica en el Tractatus Theologico-Politicus de Spinoza", en Historia de la hermenéutica.

Thémata. Revista de Filosofía №2 (2020) pp.: 57-70. 
cantidad de textos bíblicos en lo que a su interpretación concreta se refie$\mathrm{re}^{22}$, podemos extraer claramente de ellos los pilares necesarios para la fe, que expondremos más tarde.

El punto más famoso sobre la investigación histórica de la Biblia de Spinoza no es su análisis lingüístico, sino sus afirmaciones relativas a la autoría del Pentateuco y otros libros del Antiguo Testamento. Contra la creencia tradicional, Spinoza afirma, basándose en las modificaciones lingüísticas y en los hechos históricos narrados en el Pentateuco, que es imposible que Moisés fuera el autor del mismo, sino que debió ser escrito por Esdras, quien recogió los hechos, y más tarde fueron ordenados por los fariseos, tras la construcción del Segundo Templo. Esta afirmación es profundamente polémica por el hecho de que niega que la Escritura surgiera de una comunicación directa entre Dios y los profetas, sino que la aterriza a un plano mundano. Los autores de las Sagradas Escrituras fueron una suerte de historiadores que buscaron recopilar hechos notables de tal modo que sirvieran para educar al pueblo; recopilación, por lo tanto, que tenía como objetivo el ser útil para cultivar la virtud cívica, y no el recopilar los hechos históricos fidedigna y completamente. Únicamente buscaron preservar los actos moralizantes, no todas las acciones del pueblo judío.

Todo este conjunto de avatares, como ya hemos comentado, hace imposible una exégesis fidedigna de los originales bíblicos (perdidos en parte, modificados y reestructurados en su inmensa mayoría por hombres con intereses y pasiones particulares). Teniendo esto en cuenta, Spinoza defiende que debemos centrarnos en encontrar los puntos clave que nos lleven a la fe, a la creencia en Dios, y que el objetivo último del análisis de la Biblia ha de ser el de conciliar las contingencias históricas bajo las enseñanzas universales. Por ejemplo, es indiferente saber si el asesinato de Abel a manos de su hermano Caín ocurrió realmente; el objetivo de este texto es que comprendamos la aberración que supone el fratricidio.

\subsection{Fe: la aplicación práctica de la Sagrada Escritura}

No nos es posible acceder al original de la Biblia; ¿es, por lo tanto, imposible que nos llegue en la actualidad el mensaje divino que en ella se contenía? Spinoza afirma que no: que es la propia Sagrada Escritura, a través de sus enseñanzas comunes, la que nos muestra que la divinidad de este texto consiste en mostrar la verdad universal de los hombres a ellos mismos, no en comunicarles un mensaje que les sea extrínseco.

22. Spinoza, Baruch: Tratado teológico-político, p. 220 "es decir, que los fundamentos del conocimiento de las Escrituras no sólo son demasiado escasos para poder levantar sobre ellos el conocimiento completo de éstas, sino que son incluso viciosos"

Thémata. Revista de Filosofía №2 (2020) pp.: 57-70. 
En efecto, tanto la misma razón como las opiniones de los profetas y de los apóstoles proclaman abiertamente que la palabra eterna de Dios y su pacto, así como la verdadera religión están grabados por la acción divina en los corazones de los hombres ${ }^{23}$.

Es decir, que el mensaje divino de Dios sigue siendo accesible a los hombres, porque forma parte de su propia esencia.

Este mensaje, en su forma más escueta, consiste fundamentalmente en creer en Dios y en practicar el amor al prójimo. "Se llama sagrado y divino aquel objeto que está destinado a la práctica de la piedad y de la religión, y sólo será sagrado mientras los hombres hagan del mismo un uso religioso" ${ }^{24}$. En la línea de la religión civil ya marcada por Spinoza, todo aquello que mueva a creer en Dios y al amor al prójimo será tenido por religioso y sagrado. Así pues, la sacralidad de la Biblia no consiste en que posea una esencia divina autónoma, sino en que produce el sentimiento de piedad en los hombres. El Texto, por lo tanto, se define en su propiedad de divino por el efecto que produce en las personas, y no por sí mismo ${ }^{25}$.

En primera instancia, pues, sí que entendemos claramente qué significa el amor al prójimo; consiste en procurar la felicidad de nuestros semejantes, desde nuestros familiares hasta todo el género humano, pero el qué signifique "creer en Dios" para Spinoza es algo más complejo. No significa conocer la esencia divina mediante las nociones comunes, lo que es propio del saber del filósofo y sólo se obtiene mediante el racionamiento universal, ya que esto no es logrado por la mayoría de personas y es, por lo tanto, poco útil para la gobernanza del Estado. A lo que se refiere el pensador holandés es a que hay que afirmar de Dios todo aquello que nos mueva a obedecerle y obedecer su mandato divino de amor al prójimo. Las cosas que hay que pensar necesariamente de Dios para tener fe en él y obedecerle son siete: $1^{\circ}$-Existe un Dios sumamente virtuoso, $2^{\circ}$ - Dios es único, $3^{\circ}$-Dios lo conoce todo, $4^{\circ}$ - Dios es omnipotente, $5^{\circ}$ - El culto a Dios es el amor al prójimo, $6^{\circ}$ - Sólo se salvan los que obedecen a Dios, $7^{\circ}$ - Dios perdona al que se arrepiente $^{26}$. Efectivamente, mediante la creencia en estos siete preceptos queda asegurado que los hombres obedecerán a Dios (porque creerán que es sumamente bueno, que lo conoce todo y que todo lo puede) y actuarán conforme al amor al prójimo (por el precepto 5, 6 y 7). El resto de cuestiones relacionadas

23. Spinoza, Baruch: op. cit., p. 286

24. Spinoza, Baruch: op. cit., p. 289

25. Esto lo afirma tajantemente Spinoza diciendo que "De ahí se sigue, pues, que, fuera de la mente, no existe nada que sea sagrado o profano o impuro en sentido absoluto, sino sólo en relación a ella" Spinoza, Baruch: op. cit., p. 290

26. Acerca de los preceptos prácticos de la fe, ver Felipe Mac Gregor, S.J. "La teoría de la religión según Spinoza el Tratado Teológico-Político", concretamente "El Estado y la religión positiva”, en BIRA, n ${ }^{\circ} 25,1998$.

Thémata. Revista de Filosofía No62 (2020) pp.: 57-70. 
con las propiedades de Dios, como si es inmanente o trascendente al mundo, son indiferentes en relación a lo que pertenece a la actuación y el bienestar común. Podemos ver un claro correlato histórico entre la noción de religión de Spinoza y la división radical que hay entre las disputas entre teólogos y la fe mundana: efectivamente, los feligreses comunes no discurren acerca de en qué sentido Cristo era hijo de Dios, o sobre el problema de la Inmaculada concepción de la Virgen. Simplemente, creen que hay que amar al prójimo y que Dios recompensa al que hace esto.

Como conclusión que refuerza y enfatiza el concepto de religión en Spinoza como religión civil, debemos recalcar que la salvación divina, que se sustenta en la creencia en las mencionadas propiedades divinas, debe ir acompañada necesariamente de actos. Las opiniones, o la creencia meramente especulativa, no conduce a la felicidad, "Por consiguiente, no hay que creer de ninguna manera que las opiniones, por sí mismas, sin relación a las obras, contengan piedad o impiedad alguna" ${ }^{27}$, lo cual nos lleva directamente al siguiente punto, que es la aplicación política de la religión.

\section{El Estado y la religión}

La filosofía del Estado de Spinoza está fundamentada, en su procedimiento especulativo, firmemente en el pensamiento de Hobbes. Al igual que el pensador británico, Spinoza comienza su análisis del Estado por la situación que le precede, el denominado Estado de Naturaleza ${ }^{28}$. Este estado o derecho natural no es más que el comportamiento que lleva a cabo todo individuo cuando no está coaccionado por más leyes que las de su propia esencia. El derecho natural del león, así pues, sería el de cazar, dormir y realizar todo aquello que realiza cuando no está, por ejemplo, sometido al poder de los hombres en un zoológico. El estado natural, dentro de la ontología de Spinoza, no supone un estadio esencialmente distinto del estado civil, sino que es, realmente, una situación en la que el hombre no ha impuesto su poder en forma de organizaciones complejas a un ámbito de la naturaleza. El estado natural no desaparece con la aparición del estado civil, sino que éste es más bien una reconfiguración de aquél, una reorganización humana del estado natural que emplean los hombres para aumentar su poder común y su seguridad ${ }^{29}$. El estado natural es la

\section{Spinoza, Baruch: Tratado teológico-político, p. 306}

28. En Hobbes, el análisis del estado y leyes naturales se halla en los capítulos XIV y XV de la primera parte del Leviatán, mientras que la reflexión acerca del Estado civil se da en la segunda parte de la misma obra. Sobre las semejanzas y diferencias entre la filosofía política de Hobbes y la de Spinoza, ver Steven B. Smith, "Spinoza versus Hobbes: Filosofía política", en Spinoza y el libro de la vida, Biblioteca Nueva, 2013.

29. Sobre el concepto de derecho natural, en relación con la filosofía de Hobbes, ver José Ma-

Thémata. Revista de Filosofía No62 (2020) pp.: 57-70. 
definición, en relación al poder o conatus, que guía a cualquier ser:

es decir, que el derecho de naturaleza se extiende hasta donde llegue su poder. En efecto, el poder de la naturaleza es el mismo poder de Dios, que tiene el máximo derecho a todo. Pero, como el poder universal de toda la naturaleza no es nada más que el poder de todos los individuos en conjunto, se sigue que cada individuo tiene el máximo derecho a todo lo que puede o que el derecho de cada uno se extiende hasta donde alcanza su poder determinado ${ }^{30}$.

Así pues, los hombres que se guíen por la razón en vez de por la pasión se acabarán asociando y aumentando su poder hasta tal punto que se impongan al resto de la naturaleza y se perpetúen. Los hombres legan su derecho a todo (o derecho natural) a la suprema potestad, que es quien adopta el poder de la razón para gobernar. La suprema potestad no es necesariamente un individuo, ya que puede ser un grupo de ellos o incluso toda la sociedad. La diferencia, sin embargo, entre la suprema potestad y un grupo de individuos es que sus decisiones y acciones son unánimes; no hay tantas decisiones como individuos que componen la suprema potestad, sino que siempre es una. Aquel que gobierna es el que, de hecho ${ }^{31}$, puede hacer que el resto le obedezca. Los súbditos, sin embargo, no son esclavos, ya que obedecen a la suprema potestad en tanto creen que esta les beneficia, por lo menos más que el estado de naturaleza. Por lo tanto, quien daña o menoscaba en algún punto el poder del Estado está cometiendo el mayor de los crímenes, que es reducir el poder de aquella institución que le salva del estado de naturaleza irracional y en el que el hombre está subordinado a fuerzas no humanas.

La religión, por lo tanto, definida como la creencia en el conjunto de atributos divinos que obligan al amor al prójimo y la piedad, solo puede existir, o ser asegurada, dentro de un Estado civil en que una suprema potestad asegure el culto y la difusión de la religión. En el estado natural, donde los individuos sólo pueden buscar su utilidad primaria, el ser huma-

ría Rodríguez Paniagua "El pensamiento filosófico-político de Baruch de Spinoza", en Revista de Estudios Políticos, $\mathrm{n}^{\circ}$ 36, 1983.

30. Spinoza, Baruch: Tratado teológico-político, p. 331-332

Varias cosas caben comentar respecto a este fragmento: en primer lugar, la ley natural y la ley de Dios son análogas, conforme al inmanentismo divino que plantea la ontología de Spinoza. En segundo lugar, esta analogía no conlleva a un monismo, como en el estoicismo antiguo, en que todo era un mismo Logos, sino que habría que entender a Dios más bien como el conjunto infinito de entes particulares, en conflicto entre ellos. Por último, en el estado de naturaleza lo único ilegítimo respecto a un individuo es lo que, de hecho, le es imposible hacer. Por ejemplo, es ilegítimo, en el estado natural actual (el estado natural, si es el conjunto infinito de entes, y estos cambian, cambia a su vez) que un hombre tenga alas, porque, de hecho, le es imposible tenerlas.

31. El realismo político es una característica más que une a Hobbes con Spinoza: sucede lo que sucede, no lo que imaginemos que debiera suceder, y en base a ellos describimos la sociedad y su gobierno.

Thémata. Revista de Filosofía No62 (2020) pp.: 57-70. 
no está imposibilitado para este altruismo universal: como mucho, puede asociarse en pequeños grupos de beneficio. La posibilidad de la religión será mayor cuanto mayor sea el Estado que la auspicia.

Concluimos, pues, de forma general, que la religión, tanto si es revelada por la luz natural, como si lo es por la luz profética, sólo recibe fuerza preceptiva del decreto de quienes poseen el derecho del Estado y que Dios no ejerce ningún reinado especial sobre los hombres sino a través de aquellos que detentan el poder estatal ${ }^{32}$.

Es decir: Dios, como Naturaleza, solo es especial a los hombres (la llamada ley divina) en tanto que estos viven en un Estado humano, donde pueden realmente actuar bajo su razón del modo más conforme a ella posible, es decir, bajo las reglas del amor universal. La universalidad del amor está entonces delimitada a las fronteras del Estado propio o, a lo sumo, del Estado aliado.

Se podría objetar a Spinoza que la situación del cristianismo es la contraria a la que él propugna, puesto que el poder eclesiástico no está vinculado a un Estado político determinado, sino que es común a varios de ellos. Sin embargo, no es que el poder eclesiástico, diría Spinoza, exista paralelamente al civil, sino que, justamente, es este poder una suerte de fuerza opuesta que, en la medida en que intenta que los súbditos obedezcan a decretos religiosos que se oponen a la autoridad de la suprema potestad, trata de instaurarse ella misma como gobernadora. Es decir, los eclesiásticos, lo que intentan al oponerse al monarca de turno, es convertirse ellos mismos en monarcas, que les obedezcan los súbditos de aquel, y ser ellos la suprema potestad, lo que les convertiría realmente en gobernadores civiles ${ }^{33}$.

Así pues, la religión ha de subordinarse al poder civil, y fomentar la piedad será hacer que el Estado perdure y su integridad sea asegurada, para que el amor al prójimo tenga un marco en el que poder existir. Sin embargo, esta obediencia al Estado no concierne a la opinión de cada uno sobre el gobierno, sino solo a sus actos: pues es imposible para una persona renunciar a su capacidad de raciocinio, que es su propia esencia.

Por consiguiente, si nadie puede renunciar a su libertad de opinar y pensar lo que quiera, sino que cada uno es, por el supremo derecho de la naturaleza, dueño de sus pensamientos, se sigue que nunca se puede intentar en un Estado, sin condenarse a un rotundo fracaso, que los hombres sólo hablen por prescripción de las supremas potestades $^{34}$.

32. Spinoza, Baruch: Tratado teológico-político, p. 396

33. No solo es clara la referencia al conflicto entre monarquías y papado, propia de toda la Edad Media y Moderna, en el plano especulativo, sino que la mención a esta situación es explícita en el TTP: "Como este derecho fue concedido sin límite alguno al Romano Pontífice, comenzó poco a poco a tener a todos los reyes bajo su potestad, hasta que alcanzó, por fin, la máxima cumbre del Estado" Spinoza, Baruch: op. cit., p. 403

34. Spinoza, Baruch: op. cit., p. 410

Thémata. Revista de Filosofía No62 (2020) pp.: 57-70. 
Como es imposible esta sumisión total del pensamiento, el Estado mismo debe velar porque se expresen, siempre que no supongan un perjuicio para la suprema potestad, las opiniones disidentes respecto a las leyes vigentes. De este modo, el conocimiento de estas desavenencias hace que el Estado conozca mejor el ánimo de sus ciudadanos y gobierne en función de lo que es mejor para ellos. No es el Estado represor el que se perdura en la existencia, pues violenta a los súbditos y les hace odiarlo, sino el que produce amor a la nación y obediencia racional. Lo dejó claro Spinoza al afirmar que

De los fundamentos del Estado (...) se sigue, con toda evidencia, que su fin último no es dominar a los hombres ni sujetarlos por el miedo y someterlos a otro, sino, por el contrario, librarlos a todos del miedo para que vivan, en cuanto sea posible, con seguridad; esto es, para que conserven al máximo este derecho suyo natural de existir y obrar sin daño suyo ni ajeno ${ }^{35}$.

\section{Conclusión}

Podemos situar, en definitiva, la noción de religión de Spinoza dentro de lo que se denomina religión civil, como era el concepto que tenían los romanos de la misma. Una religión supeditada a los fines del Estado y enfocada a la moral, más que a las explicaciones de tipo ontológico/metafísico. Se opone claramente a la noción trascendente de religión, propia del cristianismo y de los pensadores de su tradición, como San Agustín o Leibniz.

El pensamiento de Spinoza es parejo al de Cicerón, que entiende la religión como observancia de la ley, ${ }^{36} \mathrm{o}$ al de Durkheim ${ }^{37}$, que entiende la religión como "pegamento social".

Concluimos, por lo tanto, que la religión consiste para Spinoza en la creencia imaginativa (o no deducida racionalmente) de la existencia de Dios, creencia que nos obliga a acatar el mandato de amar al prójimo. Este dictado divino encuentra su mayor posibilidad de realización dentro del Estado, en tanto que el gobierno civil es la comunidad que nos permite colaborar y ayudar al mayor número de nuestros congéneres. Así pues, la religión, en su facticidad, conduce a la obediencia civil, y debe subsumirse a los mandatos de las potestades supremas a fin de ayudar a la perpetuación del Estado y, así, permitir la realización de la felicidad humana.

35. Spinoza, Baruch: op. cit., p. 410-411

36. Cicerón, Marco Tulio: Sobre la naturaleza de los dioses, libro I.

37. Durkheim, Émile: Las formas elementales de la vida religiosa, libro III, capítulos primero y segundo.

Thémata. Revista de Filosofía No62 (2020) pp.: 57-70. 


\section{Bibliografia}

Alfredo D. Vallota, "Teología y política de la excomunión en Spinoza", Episteme, vol. 36, no.2, 2016.

Cohen, A., Moon, J. "Psychology: Atheism and moral intuitions". Nat Hum Behav 1, 0157, 2017. https://doi.org/10.1038/s41562-017-0157

Cicerón, Marco Tulio., Libro I, Sobre la naturaleza de los dioses, trad. Ángel Escobar, Madrid, España, Editorial Gredos, 1999, pp. 63-161

Delleuze, Gilles, "Evolución de Spinoza", en Spinoza: filosofía práctica, trad. Antonio Escohotado, Buenos Aires, Tusquets Editores, 2004, pp. 135- 147

Durkheim, Émile., Las formas elementales de la vida religiosa, trad. Iris Josefina Ludmer, Argentina, editorial Schapire, 1968.

Felipe Mac Gregor, S.J., "El Estado y la religión positiva", en "La teoría de la religión según Spinoza el Tratado Teológico-Político", en BIRA, $\mathrm{n}^{\circ}$ 25,1998

Ferraris, M., "La hermenéutica bíblica en el Tractatus Theologico-Politicus de Spinoza”, en Historia de la hermenéutica, Madrid, España, Taurus, 2001, pp. 45-47.

Hobbes, T., Leviatán., trad. Carlos Mellizo, Madrid, España. RBA Coleccionables, S.A.U., 2012.

Iván Ramón Rodríguez Benavides, "Capítulo 1: El Miedo Político: La Superstición”, en Pasiones, Libertad y Estado en Spinoza (tesis doctoral), Universitat de Barcelona, 2015.

José María Rodríguez Paniagua "El pensamiento filosófico-político de Baruch de Spinoza", en Revista de Estudios Políticos, n ${ }^{\circ} 36,1983$. -Santos Campos, A.: "Spinoza and the paradox of political freedom" en Revista Conatus, 8, 2014, pp. 11-24.

Spinoza, B., Ética., trad. Oscar Cohan, Barcelona, España, RBA Coleccionables, S.A.U., 2018.

Spinoza, B., Tratado teológico-político., trad. Atilano Domínguez, Madrid, España, Alianza editorial S.A., 1986.

Steven B. Smith, "Spinoza versus Hobbes: Filosofía política", en Spinoza y el libro de la vida, Biblioteca Nueva, 2013.

Víctor Sanz, "Filosofía y religión en Spinoza", Estudios Filosóficos, n¹32, 1997. 